Original Research Article

\title{
Evaluation of centrally acting skeletal muscle relaxant activity of aqueous extract of Withania somnifera (ashwagandha) roots in albino mice
}

\author{
Sarita Panigrahy*
}

\begin{abstract}
Department of Pharmacology, GVP Institute of Healthcare and Medical Technology, Maridi Valley, Marikavalasa, Visakhapatnam, Andhra Pradesh, India
\end{abstract}

Received: 22 October 2018 Revised: 14 November 2018 Accepted: 29 November 2018

*Correspondence to: Dr. Sarita Panigrahy, Email: sarita1987july@ gmail.com

Copyright: () the author(s), publisher and licensee Medip Academy. This is an openaccess article distributed under the terms of the Creative Commons Attribution NonCommercial License, which permits unrestricted noncommercial use, distribution, and reproduction in any medium, provided the original work is properly cited.

\begin{abstract}
Background: Skeletal muscle relaxants are used to treat both muscle spasm and spasticity, acting both as antispasmodic and antispasticity agents. In past studies some polyherbal formulations containing ashwagandha have shown skeletal muscle relaxant activity and fat extract of ashwagandha showed skeletal muscle relaxant activity in experimental animal models. This study is designed to evaluate the skeletal muscle relaxant activity of aqueous extract of Withania somnifera (ashwagandha) roots in albino mice, as the literature regarding them is limited.

Methods: Standard drug (diazepam) and different doses of Aqueous extract of ashwagandha $(50,100,150 \mathrm{mg} / \mathrm{kg})$ were given orally to albino mice. Skeletal muscle relaxant activity was assessed by Rota-rod apparatus. The fall off time from the rotating rod was noted for each group after 1 hour of drug administration. The difference in fall off time from the rotating rod between the standard and treated mice was taken as an index of muscle relaxation.

Results: The test extract at doses $(50 \mathrm{mg} / \mathrm{kg}, 100 \mathrm{mg} / \mathrm{kg}$ and $150 \mathrm{mg} / \mathrm{kg}$ ) showed highly significant reduction in the time spent by the animals on revolving rod in rota rod test when compared to baseline ( $p<0.0001)$. As compared with diazepam, aqueous extract $(150 \mathrm{mg} / \mathrm{kg})$ showed almost equal reduction in the time spent by the animals on revolving rod in rota rod test.

Conclusions: This study indicates that the aqueous extract of ashwagandha possess central skeletal muscle relaxant activity. The results are promising for further investigation of efficient skeletal muscle relaxant activity.
\end{abstract}

Keywords: Ashwagandha, Albino mice, Diazepam, Rota rod test

\section{INTRODUCTION}

Drugs that affect skeletal muscle function include two different therapeutic groups 1) those used during surgical procedures and in intensive coronary unit (ICU) to produce muscle paralysis (that is - neuromuscular blockers) and 2) those to reduce spasticity in a variety of painful conditions (that is - spasmolytics - traditionally called as skeletal muscle relaxants). ${ }^{1}$ When the central nervous system neuromuscular junction has interruptions in normal transmission of nerve stimuli, skeletal muscle spasms and muscle spasticity occur. ${ }^{2}$ It is characterized by muscle over activity which, if left untreated, may lead to muscle and soft tissue contracture.

Centrally acting and directly acting muscle relaxants accompanied by physical therapy are the drugs of choice for relief of muscle spasticity. Dantrolene and diazepam are mostly the drugs of choice. Studies have shown that the skeletal muscle relaxants to be more effective than placebo in the treatment of acute painful musculoskeletal disorders and muscle spasm, while efficacy was less consistent when treating chronic disorders. When the skeletal muscle relaxants were used in combination with analgesics, pain 
relief is superior to either agent used alone. Centrally acting skeletal muscle relaxants are generally prescribed either as single agents or as components of combination products. The Food and Drug Administration has approved these medications as adjuncts to rest and physical therapy for relief of acute, painful musculoskeletal problems. The side effects of antispasmodic agents and antispasticity agents cause them to be used with caution. Previous reports have shown that $10-20 \%$ of adults suffer from insomnia. Withania somnifera, better known as Ashwagandha or "Indian ginseng," has been a staple of Ayurvedic medicine for over 3000 years. ${ }^{3}$ The botanical name of Ashwagandha is Withania somnifera belonging to solanaceae. ${ }^{4}$ The name Ashwagandha is from the Sanskrit language and is a combination of the word ashva, meaning horse, and gandha, meaning smell. The root has a strong aroma that is described as "horse-like." In Ayurveda it is classified as rasayana (Rejuvenation) and expected to promote physical and mental health, rejuvenate the body in debilitated conditions and increases longevity. ${ }^{5}$ Various studies in animal models have shown that ashwagandha has anticonvulsant, antidepressant, antianxiety, hepatoprotective, anti - inflammatory, immunemodulatory activity. ${ }^{6-11}$ As there are limited studies regarding the skeletal muscle relaxant activity of Ashwagandha. Therefore, this study is designed to evaluate the skeletal muscle relaxant activity of aqueous extract of Withania somnifera (Ashwagandha) roots in albino mice.

\section{METHODS}

The present study was carried out in the postgraduate research laboratory, Department of pharmacology, Alluri Sita Ramaraju Academy of Medical Sciences, Eluru, with the approval of institutional ethical committee.

\section{Drugs}

Normal saline, ashwagandha roots (aqueous extract) from Laila Nutraceuticals, Vijayawada. Aqueous extract contains total Withanolides\% assay by High Performance Liquid Chromatography, HPLC $(0.15 \%)$, and diazepam tablets $(10 \mathrm{mg})$.

\section{Animal}

Swiss albino mice of the either sex weighing 40-50gms were used. The animals were procured from central animal house, Department of pharmacology, Alluri Sita Ramaraju Academy of Medical Sciences, Eluru and maintained in standard cages with free access to food and water. Permission from Institutional Animal Ethics Committee constituted for the purpose of CPCSEA Government of India was taken.

\section{Experimental design}

Animals of each group that remain on the revolving rod for 2 or more minutes in four trials carried out in two days during morning and afternoon sessions were selected and divided into different groups. Mice were divided into five groups consisting of 6 animals each. Group I served as control which received normal saline $10 \mathrm{ml} / \mathrm{kg}$, group II received standard drug diazepam at a dose of $5 \mathrm{mg} / \mathrm{kg}$, group III, IV and $\mathrm{V}$ received the aqueous extract of Ashwagandha orally at a dose of 50, 100 and $150 \mathrm{mg} / \mathrm{kg}$. After the administration of control, standard and test material the fall off time from the rotating rod was noted after 60minutes. The difference in the fall off time from the rotating rod between the standard and the treated mice was taken as an index of muscle relaxation. Recording the fall off time from the rotating rod by using rota rod apparatus devised by Dunham MW et al. ${ }^{12}$

\section{Statistical analysis}

The data was entered through Microsoft Excel - 2007 software and analysed by the Descriptive statistics like Mean, standard deviation and standard error and the quantitative data was analysed by using the statistical test like $\mathrm{t}$ - test, paired test and ANOVA one - way classification. $\mathrm{P}$ value $<0.05$ considered significant.

\section{RESULTS}

All obtained data were noted and processed for Statistical analysis. As seen from Table 1, The effect of muscle relaxant activity of aqueous extract have been shown in Table 1 , at a dose of $50,100,150 \mathrm{mg} / \mathrm{kg}$ body weight produced a significant decrease in fall off time $(30.4 \%$, $61.7 \%, 74.9 \%$ respectively) after 60minutes of oral administration of test drug. Similarly, animals with diazepam $(5 \mathrm{mg} / \mathrm{kg})$ i.p shows a significant decrease in fall off time $(78.5 \%)$ after 60 minutes of standard drug administration.

As seen in Table 2, the mean falls of time from the rotating rod after giving standard drug (diazepam - $10 \mathrm{mg} / \mathrm{kg}$ ) is $45.3 \pm 3.3 \mathrm{Sec}$ and after giving test drug (aqueous extract 50 and $100 \mathrm{mg} / \mathrm{kg}$ ) are 145 and $80 \mathrm{sec}$ respectively. So, authors conclude that aqueous extracts of ashwagandha at a dose of $50 \mathrm{mg} / \mathrm{kg}, 100 \mathrm{mg} / \mathrm{kg}$ are having less skeletal muscle relaxant activity as compared to standard drug. And the percentage of muscle relaxant effect of diazepam is $78.5 \%$ when compared to aqueous extract at dose of 50 and $100 \mathrm{mg} / \mathrm{kg}$ (30.4\% and $61.7 \%$ respectively).

But at a dose of test drug $(150 \mathrm{mg} / \mathrm{kg})$ the mean falls off time from rotating rod is $53.16 \mathrm{sec}$. when compared to diazepam, there is less significant difference between their mean responses. This result concludes that aqueous extract $(150 \mathrm{mg} / \mathrm{kg})$ was found to be effective and it exhibited activity similar to that of diazepam i.e the percentage of muscle relaxant effect of diazepam is $78.5 \%$ and that of aqueous extract at dose of $150 \mathrm{mg} / \mathrm{kg}$ is $74.9 \%$.

As seen in Figure 1, the mean falls of free ride time before giving standard drug (diazepam) is $211 \mathrm{Sec}$ and the mean fall of free ride time after giving diazepam is $45.3 \mathrm{Sec}$. This 
shows there is a significant difference in the mean fall of free ride time on the revolving rod in the rota rod test between the before and after standard drug (diazepam) administration, indicating the skeletal muscle relaxant activity of diazepam. Similarly, there are significant differences in the mean fall of free ride time on the revolving rod in the rotarod test between before and after test drug i.e. (Aqueous extract - 50mg/kg, 100mg/kg,
$150 \mathrm{mg} / \mathrm{kg}$ ) administration. i.e. the mean falls off time from the rotating rod before giving aqueous extract at doses of $50,100,150 \mathrm{mg} / \mathrm{kg}$ are $208.3 \mathrm{sec}, 209 \mathrm{Sec}, 212.3 \mathrm{Sec}$ and after giving test drug are $145 \mathrm{Sec}, 80 \mathrm{sec}$ and $53.16 \mathrm{Sec}$ respectively, thus indicates the skeletal muscle relaxant activity of aqueous extract of ashwagandha at different doses.

Table 1: Centrally acting muscle relaxant activity of standard and aqueous extract of test drug on mice ( $n=6$; in each group).

\begin{tabular}{|c|c|c|c|c|}
\hline \multirow[t]{2}{*}{ Groups } & \multirow[t]{2}{*}{ Dose (mg/kg) } & \multicolumn{2}{|c|}{$\begin{array}{l}\text { Time (sec) of animals remained without } \\
\text { falling from rotating rod }\end{array}$} & \multirow[t]{2}{*}{$\%$ of myorelaxation } \\
\hline & & Before & After & \\
\hline \multirow{6}{*}{ Diazepam (standard) } & \multirow{6}{*}{10} & 194 & 40 & \multirow{6}{*}{$78.5 \%$} \\
\hline & & 200 & 55 & \\
\hline & & 220 & 40 & \\
\hline & & 196 & 52 & \\
\hline & & 226 & 35 & \\
\hline & & 230 & 50 & \\
\hline \multirow{6}{*}{ Aqueous extract } & \multirow{6}{*}{50} & 190 & 145 & \multirow{6}{*}{$30.4 \%$} \\
\hline & & 220 & 130 & \\
\hline & & 180 & 120 & \\
\hline & & 200 & 140 & \\
\hline & & 220 & 165 & \\
\hline & & 240 & 170 & \\
\hline \multirow{6}{*}{ Aqueous extract } & \multirow{6}{*}{100} & 192 & 100 & \multirow{6}{*}{$61.7 \%$} \\
\hline & & 222 & 90 & \\
\hline & & 184 & 70 & \\
\hline & & 202 & 65 & \\
\hline & & 222 & 80 & \\
\hline & & 232 & 75 & \\
\hline \multirow{6}{*}{ Aqueous extract } & \multirow{6}{*}{150} & 200 & 45 & \multirow{6}{*}{$74.9 \%$} \\
\hline & & 230 & 40 & \\
\hline & & 226 & 81 & \\
\hline & & 196 & 55 & \\
\hline & & 202 & 50 & \\
\hline & & 220 & 48 & \\
\hline
\end{tabular}

Table 2: Effect of aqueous extract of ashwagandha on muscle coordination using rotarod apparatus.

\begin{tabular}{|c|c|c|c|c|}
\hline \multirow[t]{2}{*}{ Groups } & \multirow{2}{*}{$\begin{array}{l}\text { Dose } \\
(\mathrm{mg} / \mathrm{kg})\end{array}$} & \multicolumn{2}{|c|}{ Mean \pm SE fall off time from rotating rod (sec) } & \multirow{2}{*}{$\begin{array}{l}\text { Percentage of } \\
\text { myorelaxation }(\%)\end{array}$} \\
\hline & & Before & After & \\
\hline Diazepam (standard) & 10 & 211 & 45.3 & 78.5 \\
\hline Aqueous extract & 50 & 208.3 & 145 & 30.4 \\
\hline Aqueous extract & 100 & 209 & 80 & 61.7 \\
\hline Aqueous extract & 150 & 212.3 & 53.16 & 74.9 \\
\hline
\end{tabular}

The results are expressed as means \pm SEM; Differences in mean values between groups was analysed by a one way analysis of variance (ANOVA). Statistical significance was assessed as $\mathrm{p}<0.05$.

As seen in Figure 2, the percentage of muscle relaxant effect of diazepam $(10 \mathrm{mg} / \mathrm{kg})$ is $78.5 \%$ and that of Aqueous extract at doses of $50 \mathrm{mg} / \mathrm{kg}, 100 \mathrm{mg} / \mathrm{kg}$ and
$150 \mathrm{mg} / \mathrm{kg}$ are $30.38 \%, 61.7 \%$ and $74.9 \%$ respectively. So, this indicates that Aqueous extract of Ashwagandha at doses of $50 \mathrm{mg} / \mathrm{kg}$ and $100 \mathrm{mg} / \mathrm{kg}$ are having less skeletal 
muscle relaxant activity when compared to standard drug diazepam $(10 \mathrm{mg} / \mathrm{kg})$. But the higher dose of the Aqueous extract $(150 \mathrm{mg} / \mathrm{kg})$ showed a greater inhibition comparable with standard drug (diazepam). Thus, the three different doses of aqueous extract showed a dose dependent increase in percentage of myorelaxation i.e. $30.38 \%, 61.7 \%$ and $74.9 \%$ respectively. Maximum relaxation was observed with the dose of $150 \mathrm{mg} / \mathrm{kg}$ of aqueous extract.

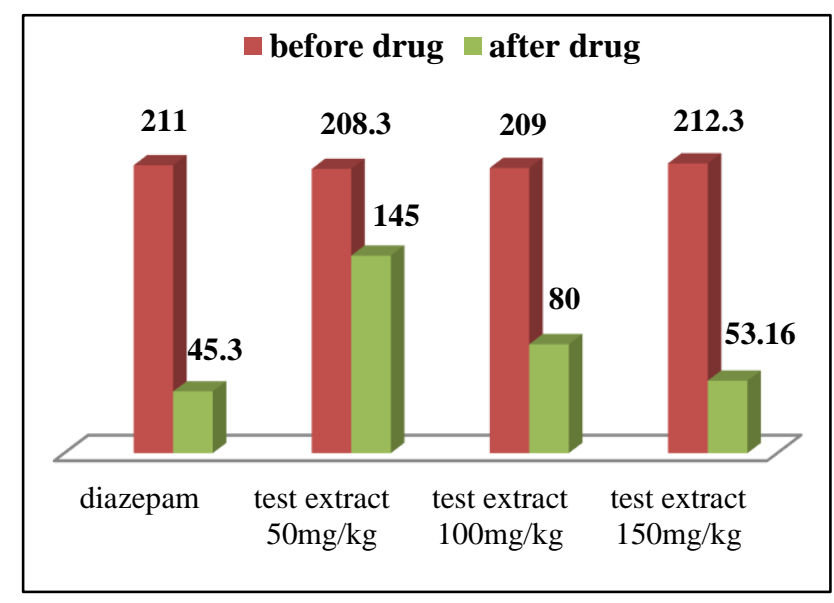

Figure 1: Fall of free ride time with diazepam and different doses of test drug.

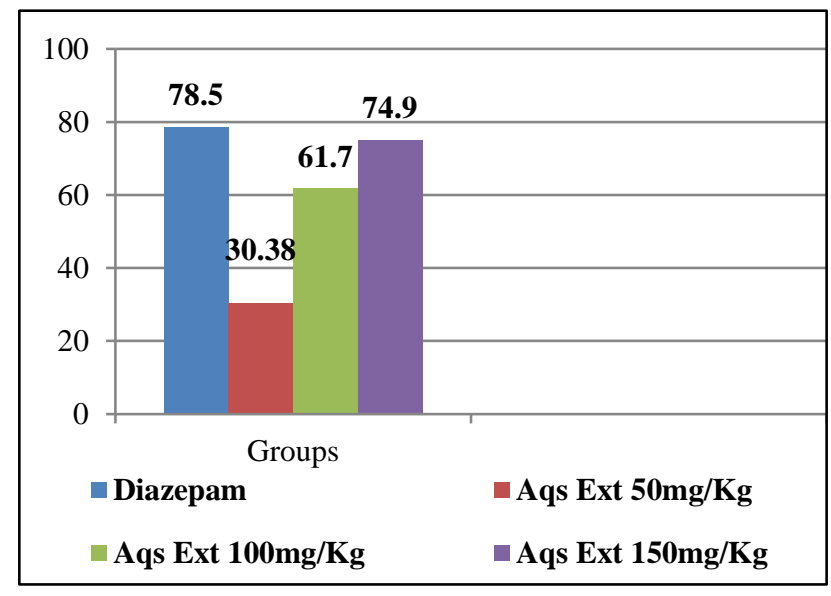

Figure 2: Percentage of muscle relaxant effect of aqeuous extract (test drug) at doses of $50 \mathrm{mg} / \mathrm{kg}$, $100 \mathrm{mg} / \mathrm{kg}$ and $150 \mathrm{mg} / \mathrm{kg}$.

\section{DISCUSSION}

In a study the fat extract of Withania somnifera (ashwagandha) root was evaluated for anxiolytic activity. ${ }^{13}$ Two different doses (100 and $200 \mathrm{mg} / \mathrm{kg}$ ), a fat extract of Withania somnifera was suspended in $1 \%$ gum acacia solution. The results of the study concluded that in the rota rod test, Withania somnifera $(100 \mathrm{mg} / \mathrm{kg}$ and $200 \mathrm{mg} / \mathrm{kg}$ ) significantly reduced the time spent by the animals on revolving rod in rota rod test when compared to control ( $\mathrm{P}$ value $<0.01)$. Low dose of drug $(100 \mathrm{mg} / \mathrm{kg})$ did not show any significant effect at 30 and $45 \mathrm{~min}$ time intervals. But in this present study low dose of Withania somnifera $(50$ $\mathrm{mg} / \mathrm{kg}$ ) also showed significant reduction in the time spent by the animals on revolving rod in the rota rod test after 60 minutes of test drug administration when compared to baseline.

In another study the polyherbal formulation consisting of hydro-alcoholic extract of leaves of Butea frondosa, roots of Withania somnifera (ashwagandha), aerial parts of Convolvulus Pruricalis, seeds of Nigella sativa, rhizomes of Curcuma longa, and leaves of Azadirachta indica, all of these drugs were screened for anti - depressant, analgesic, muscle relaxant activities. ${ }^{14}$ The dose of HAEPHF (Hydro alcoholic extracts of polyherbal formulation) used were 500,1000 and $2000 \mathrm{mg} / \mathrm{kg}$. The results of the study concluded that animals treated with HAEPHF $(500 \mathrm{mg} / \mathrm{kg})$ did not show significant decrease in time spent on rotating rod while those treated with HAEPHF (1000 and $2000 \mathrm{mg} / \mathrm{kg}$ ) showed more significant decrease in time spent on revolving rod indicating the muscle relaxant activity. The test drug was found to be comparable to standard drug, diazepam $(2 \mathrm{mg} / \mathrm{kg})$.

In another study, the effect of the alkaloidal fractions (acetone, alcohol and water soluble) of Withania somnifera on central nervous system was studied. ${ }^{15}$ The results of this study concluded that water soluble alkaloid fraction in doses higher than $5 \mathrm{mg} / \mathrm{kg}$ dose, produced a weak generalised sedative and depressant effect on central nervous system, the effect was more significant with dose of $20 \mathrm{mg} / \mathrm{kg}$. And the alcohol soluble alkaloid fraction in dose of 32 to $64 \mathrm{mg} / \mathrm{kg}$, did not exhibit any significant neurophamacological actions. So, this study concluded that most of the neurophamacological actions of the total Alkaloids (ashwagandholine) are due to the acetone soluble alkaloidal fraction. Other two fractions, i.e. Alcohol soluble and water-soluble alkaloidal fractions are devoid of any neuropharmacological actions. In equivalent doses, acetone soluble alkaloidal fraction is 1.15 times more active than the total alkaloids. In this present study low dose of aqueous extract of Withania somnifera (50 $\mathrm{mg} / \mathrm{kg}$ ) showed significant reduction in the time spent by the animals on revolving rod in the rota rod test after 60 minutes of test drug administration when compared to baseline.

In present study, aqueous extracts at the doses of $50 \mathrm{mg} / \mathrm{kg}$, $100 \mathrm{mg} / \mathrm{kg}$ and $150 \mathrm{mg} / \mathrm{kg}$ showed highly significant reduction in the time spent by the animals on revolving rod in rotarod test when compared to baseline $(\mathrm{p}<0.0001)$ which is highly significant. But when compared with standard drug diazepam, diazepam showed highly significant reduction in the time spent by the animals on revolving rod in rota rod test as compared with the two doses of aqueous extract i.e. (50mg/ $/ \mathrm{kg}$ and $100 \mathrm{mg} / \mathrm{kg}$ ). This concludes that diazepam is having better skeletal muscle relaxant activity. But aqueous extract at a dose of $150 \mathrm{mg} / \mathrm{kg}$ have showed almost equal reduction in the time spent by the animals on revolving rod in rota rod test as with standard drug diazepam. And the three different doses of aqueous extract showed a dose dependent increase in 
muscle relaxant activity. Maximum muscle relaxation was observed with dose of $150 \mathrm{mg} / \mathrm{kg}$ of aqueous extract.

The major biochemical constituents of ashwagandha root are steroidal alkaloids and steroidal lactones in a class of constituents called withanolides. About 12 alkaloids, 35 withanolides, and several sitoindosides from this plant have been isolated and studied. A sitoindoside is a withanolide containing a glucose molecule at carbon 27 .

Much of Ashwagandha's pharmacological activity has been attributed to two main withanolides - withaferin A and withanolide D.

Earlier reports on the chemical constituents of plants and their pharmacology suggest that plants containing withaferin $\mathrm{A}$ and withanolide $\mathrm{D}$ possess activity against many CNS disorders.

Further biochemical and pharmacological studies are necessary to establish the exact chemical constituents and their mechanisms of action.

Further human studies are needed to prove the safety and efficacy of long-term administration of Aqueous extract of Withania somnifera roots.

\section{CONCLUSION}

Previous studies with polyherbral formulations containing Ashwagandha as one of the ingredients and fat extract of Ashwagandha have shown skeletal muscle relaxant activity. In the present study aqueous extracts of Ashwagandha roots have evaluated for its skeletal muscle relaxant activity by using rota rod method.

Funding: No funding sources

Conflict of interest: None declared

Ethical approval: The study was approved by the Institutional Ethics Committee

\section{REFERENCES}

1. Bertam G.Katzung Susan B.Masters Anthony J. Trevor Basic and clinical pharmacology.12th ed. 2011:465.

2. Eugenia M.Fulcher Robert M.Fulcher pharmacology principles and applications.3rd ed. 2003:413.

3. Withania somnifera (L.) Dunal. Germplasm Resources Information Network - (GRIN). Beltsville, Maryland: USDA, ARS, National Genetic Resources Program. National Germplasm Resources Laboratory. Accessed 29 November 2011.

4. Mishra LC, Singh BB, Dagenais S. Scientific basis for the therapeutic use of Withania somnifera (ashwagandha): a review. Alternative Med Rev. 2000 Aug 1;5(4):334-46.
5. Venkataraghavan S, Seshadri C, Sundaresan TP, Revathi R, Rajagopalan V, Janaki K. The comparative effect of milk fortified with Aswagandha, Aswagandha and Punarnava in children-a doubleblind study. J Res Ayur Sid. 1980;1:370-85.

6. Kulkarni SK, Akula KK, Dhir A. Effect of Withania somnifera Dunal root extract against pentylenetetrazol seizure threshold in mice: possible involvement of GABAergic system, Indian J Experimental Biol. 2008;46:465-469.

7. Gupta GL, Rana AC. Protective effect of Withania somnifera dunal root extract against protracted social isolation induced behavior in rats. Indian J Physiol Pharmacol. 2007;51(4):345-53.

8. Shah PC, Trivedi NA, Bhatt JD, Hemavathi KG. Effect of Withania somnifera on forced swimming test induced immobility in mice and its interaction with various drugs. Indian $\mathrm{J}$ Physiol Pharmacol. 2006;50(4):409-15.

9. Sabiba EP, Rasool M, Vedi M, Navaneethan D, Ravichander M, Parthasarathy $\mathrm{P}$, et al. Hepatoprotective and antioxidant potential of Withania somnifera against paracetamol-induced liver damage in rats. Int J Pharm Pharm Sci. 2013;5(2):64851

10. Begum VH, Sadique J. Effect of Withania somnifera on glycosaminoglycan synthesis in carrageen ininduced air pouch granuloma. Biochem Med Metab Biol. 1987(Dec); 38:272-277.

11. Ziauddin M, Phansalkar N, Patki P, Diwanay S, Patwardhan B. Studies on the immunomodulatory effects of Ashwagandha. J Ethnopharmacol. 1996 Feb $1 ; 50(2): 69-76$.

12. Dunham NW, Miya TS. A note on a simple apparatus for detecting neurological deficit in rats and mice. $\mathrm{J}$ Am Pharmaceut Assoc. 1957 Mar 1;46(3):208-9.

13. Jayanthi MK, Prathima C, Huralikuppi JC, Suresha RN. Preliminary Studies on Anxiolytic activities of Withania somnifera (Ashwagandha) fat extract in experimental animal models, National J Basic Med Sci.2012(oct-dec);III(2):134-40.

14. Mohammed A. Assessment of polyherbal formulations' for CNS activities. Int J Polypharmacy. $2013 ; 4(2): 148$.

15. Prasad S, Malhotra CL. Studies on Withania ashwagandha Kaul (Part-VI)- the effect of the alkaloidal fractions (acetone, alcohol and water soluble) on the central nervous system. Indian $\mathbf{J}$ Physiol Pharmacol. 1968;12(4):175-81.

Cite this article as: Panigrahy S. Evaluation of centrally acting skeletal muscle relaxant activity of aqueous extract of Withania somnifera (ashwagandha) roots in albino mice. Int J Basic Clin Pharmacol 2019;8:157-61. 